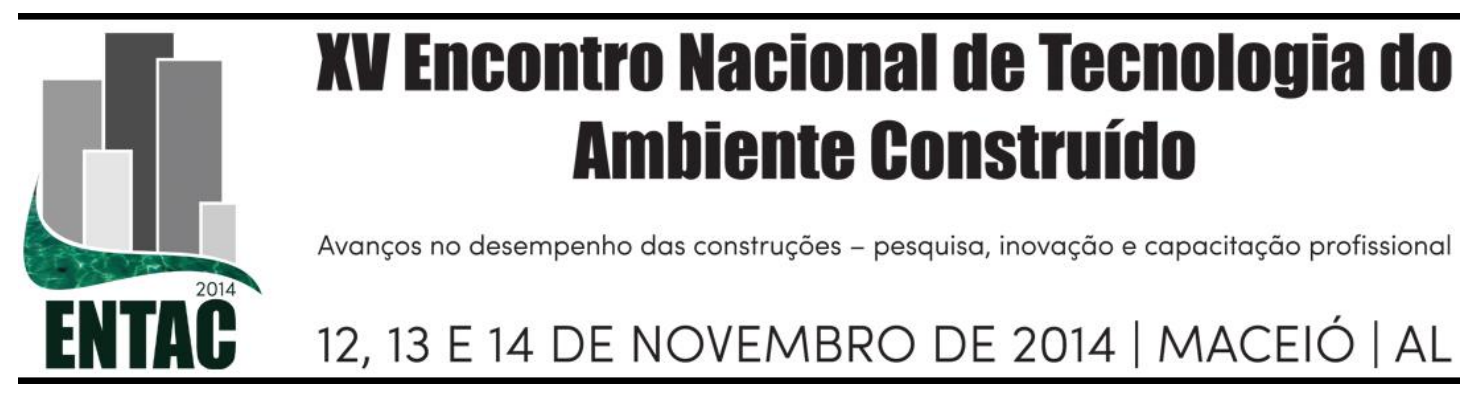

\title{
ESTUDO SOBRE AS PATOLOGIAS OCORRIDAS DEVIDO A REAÇÃO ÁLCALI-AGREGADO NO GINÁSIO AECIM TOCANTINS EM CUIABÁ - MT
}

\author{
VALIN JR, Marcos de Oliveira(1); RIBEIRO, Karyn Ferreira Antunes (2). \\ (1) Professor Esp. IFMT - Campus Cuiabá, e-mail: marcos.valin@cba.ifmt.edu.br \\ (2) Professora Esp. IFMT - Campus Cuiabá, e-mail: karyn.ribeiro@cba.ifmt.edu.br
}

\begin{abstract}
RESUMO
Construído em Cuiabá, capital do estado de Mato Grosso, no ano de 2007, o Ginásio Poliesportivo Professor Aecim Tocantins, trouxe grandes competições internacionais para cidade e também devido sua premiada arquitetura e localização tornou-se um cartão postal. A estrutura de cobertura possui dois arcos principais, que são apoiados em quatro pilares principais, os quais apresentaram físsuras já nos primeiros meses após conclusão da obra, sendo realizado um reforço estrutural nos pilares em 2008, que não foi bem sucedido, pois logo surgiram novas fissuras com as mesmas características. Após verificações através de consultoria de especialistas de referência nacional em recuperação de estruturas, diversos ensaios realizados como análise física e química de testemunhos extraídos e determinação do teor de sulfatos pela amostra de pó, análise estrutural e de documentação técnica da época da obra fornecidas pela construtora, concreteira e demais fornecedores, verificou-se que as fissuras não estavam relacionados com o dimensionamento, mas na verdade com os materiais utilizados, concluindo-se que as expansões que davam origem as fissuras eram resultados de reação álcali-agregado. Para solucionar a patologia foi realizado um novo reforço estrutural, porém desta vez com a utilização de um revestimento com chapa metálica e injeção de resina entre a chapa e o concreto, impedindo que o concreto entre em contato com qualquer tipo de umidade, que é necessária para as expansões. Este trabalho tem por objetivo apresentar o estudo de caso, com detalhes dos procedimentos adotados pela empresa executora da obra e consultores contratados durante a investigação e solução do problema patológico, visando contribuir para outras obras e normatizações futuras, visto a importância do estudo da reação álcali-agregado para a durabilidade de estruturas de concreto, fator determinante para a sustentabilidade das construções, visto que além dos altos custos, as manutenções e reforços estruturais implicam na utilização de novos materiais e na produção de resíduos.
\end{abstract}

Palavras-chave: reação álcali-agregado; reações expansivas; durabilidade.

\begin{abstract}
Built in Cuiaba, capital of Mato Grosso, in 2007, the Gym Aecim Tocantins brought major international competitions to the city and because of its architecture and location has become a postcard. The roof structure has two main arches, which are supported on four main pillars, which showed cracks in the first months after completion of the work being performed a reinforcement that was not successful, because new cracks soon emerged. After checks by consulting experts from national reference and various tests, it was found that the cracks were not related to the design, but in fact with the materials used, concluding that the expansions that gave rise cracks were the result of alkali-aggregate reaction. To solve the pathology was made a new structural reinforcement with the use of a coating with sheet metal, preventing the concrete contact with moisture, which is needed for the expansions. This paper presents the procedures adopted by the company performing the work and consultants engaged in the investigation and solution of the problem, aiming to contribute to other studies and future norms, since the importance of the study of alkali-aggregate reaction to the durability of concrete structures, factor crucial for the sustainability of concrete.
\end{abstract}

Keywords: Alkali-aggregate reaction, expansions reaction, durability. 


\section{INTRODUÇÃO}

O Ginásio Aecim Tocantins é um ginásio poliesportivo situado na cidade de Cuiabá Mato Grosso. Foi inaugurado em 31 de maio de 2007 e de acordo com a SECRETARIA DE ESPORTES - GOVERNO DO ESTADO DE MT (2013), possui capacidade para 11 mil pessoas, refeitório para 132 pessoas, auditório com 70 lugares, alojamento com 220 leitos, 11 cabines de imprensa, salas administrativas, tribuna de honra e quadra poliesportiva oficial, atendendo as modalidades de futsal, voleibol, handebol, basquetebol, podendo também ser utilizado para a realização de torneios de artes marciais, espetáculos de dança, teatro e eventos culturais, conforme figuras 01 e 02 .

Como marco oficial de inauguração de um dos mais modernos ginásios poliesportivos do Centro-Oeste foi realizado a LIGA MUNDIAL DE VÔLEI 2007. O ginásio também já sediou a Copa América de Voleibol de 2008 e a Copa América de Basquetebol Feminino de 2009, entre outros grandes eventos.

\section{Figuras 01 e 02 - Ginásio Aecim Tocantins}
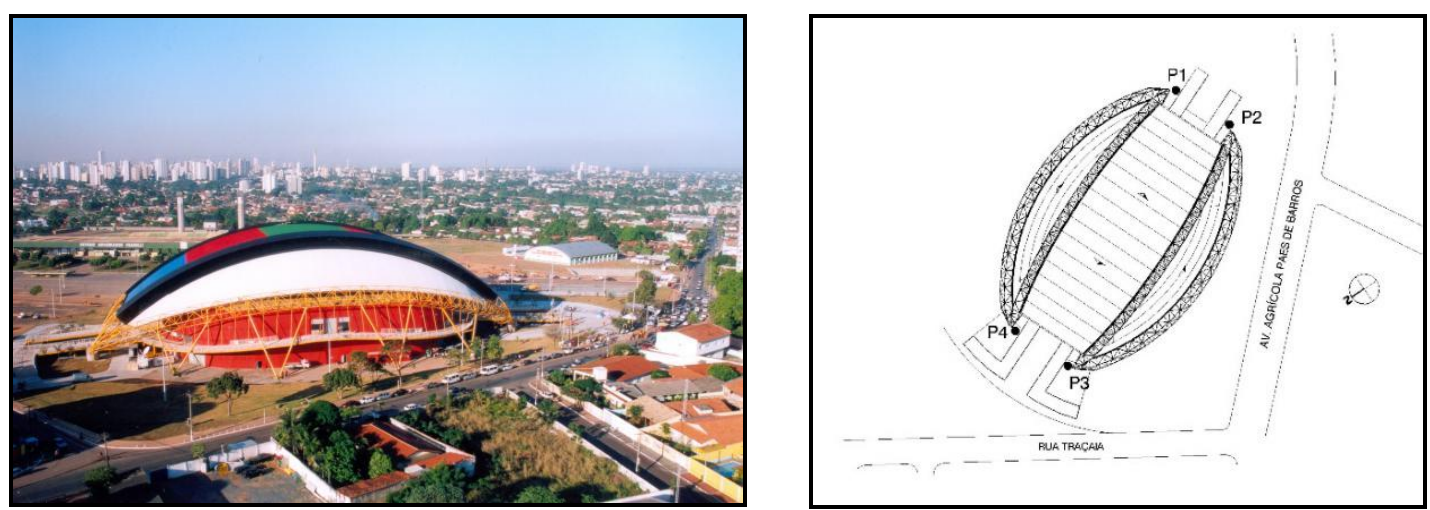

Fonte: Lotufo Engenharia (2010).

Este artigo tem por objetivo apresentar as manifestações patológicas, bem como os ensaios realizados durante o processo de investigação e as correções adotadas nos quatro pilares de apoio dos arcos da estrutura metálica de cobertura do ginásio, que começaram a se manifestar através de fissuras poucos meses após a conclusão da obra, devido a expansões originadas de reação álcali agregado.

Um dos mecanismos de deterioração do concreto, com menor intensidade de ocorrência do que a corrosão das armaduras, mas não menos relevante, é a reação álcali-agregado (RAA). Este fenômeno foi descoberto pela primeira vez nos Estados Unidos no início da década de 40 , sendo ainda pouco compreendido devido à sua elevada complexidade. As suas consequências ainda não são um consenso no meio técnico, apesar do grande número de pesquisas já realizadas nos últimos anos (GALLO et al, 2007).

Segundo CARMONA FILHO e GARCIA CARMONA (2011) a reação álcali agregado ocorre em concretos e argamassas nos quais os agregados, graúdos ou miúdos, apresentam certas características que lhe conferem reatividade com os álcalis presentes no cimento $(\mathrm{Na} 2+, \mathrm{K} 2+)$, associados aos íons hidroxila $(\mathrm{OH}-)$. O resultado da reação é um produto de características expansivas, comumente chamado de gel de sílica, que provoca o surgimento de tensões internas de tração no concreto, dando origem a fissuras, cuja distribuição normalmente é errática. No Brasil os relatos de RAA se limitavam aos casos de barragens construídas nas décadas de 60 e 70 . Porém 
recentemente casos com sérias consequências têm sido constatados em outros tipos de edificações incluindo pontes, edifícios residenciais e comerciais, pavimentação de concreto etc.

\section{INVESTIGAÇÃO E PRIMEIRAS PROVIDENCIAS}

Como apresentado na figura 02, os quatro pilares (P1, P2, P3 e P4) de apoio dos arcos da estrutura metálica de cobertura têm $3,44 \mathrm{~m}$ de diâmetro e aproximadamente 3,9 $\mathrm{m}$ de altura a partir dos blocos de apoio, sendo a armação longitudinal de projeto constituída de 56 barras longitudinais de $20 \mathrm{~mm}$ e estribos de $8 \mathrm{~mm}$ a cada $10 \mathrm{~cm}$ e o fck de 25 $\mathrm{MPa}$.

As primeiras fissuras apresentadas no ano de 2008 se iniciavam nos vértices das placas de apoio e se prolongavam na vertical, algumas chegando à base dos pilares, sendo que o engenheiro projetista na ocasião decidiu realizar um reforço da estrutura, que consistiu na demolição de faixas de $30 \mathrm{~cm}$ com incorporação de 5 estribos de $8 \mathrm{~mm}$ ao longo da altura e uma malha de barras de $10 \mathrm{~mm}$ com $15 \times 15 \mathrm{~cm}$ de espaçamento na face superior (figura 03). O fck do concreto utilizado para o reforço foi de $30 \mathrm{MPa}$, e as fissuras principais foram injetadas com resina epóxi, sendo que esse processo de recuperação foi realizado entre junho e agosto de 2008.

\section{Figura 03 - Esquema mostrando a armadura longitudinal original (vermelho) e}

$$
\text { estribos de reforço (azul). }
$$

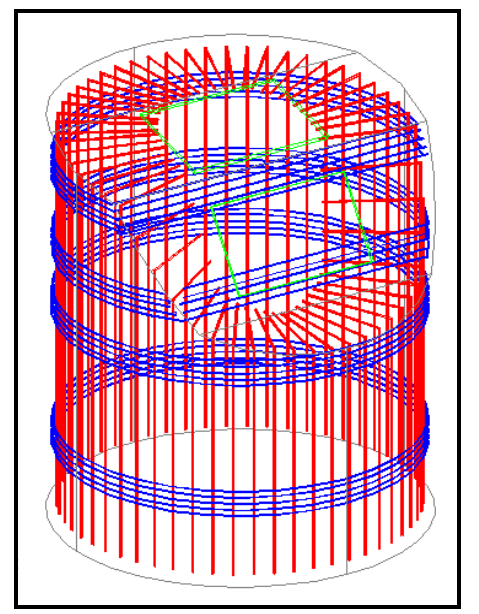

Fonte: Lotufo Engenharia e Construções Ltda. (2010).

Apesar do reforço realizado, novas fissuras surgiram, sendo parte delas na mesma região daquelas de antes do reforço (ver figuras 04, 04A, 04B e 04C). 
Figura 04 - Esquema da tipologia geral das fissuras observadas após o reforço

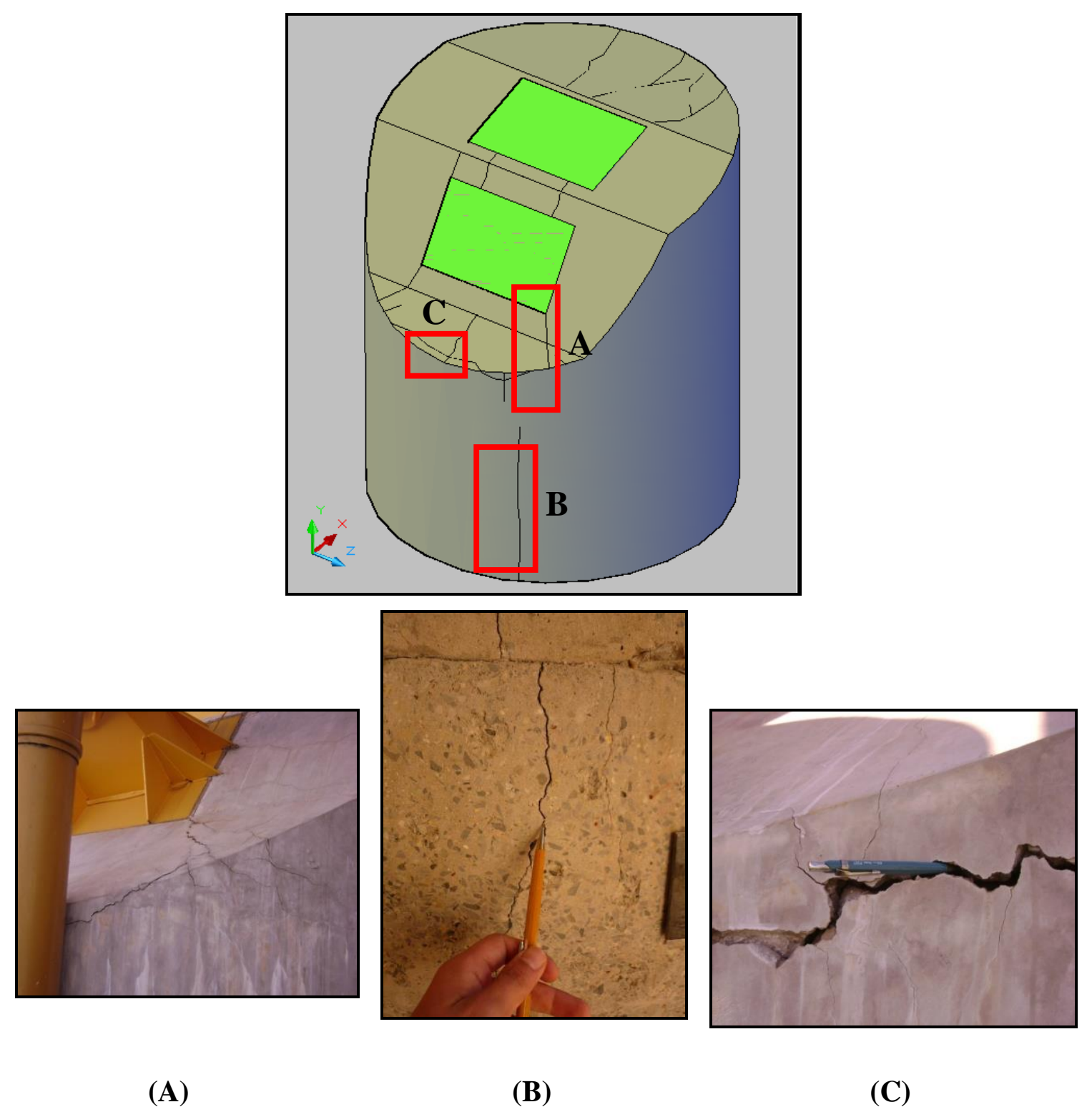

Fonte: Lotufo Engenharia e Construções Ltda. (2010).

Como primeiro reforço não teve sucesso, fez-se necessário a contratação de um consultoria. Para a realização de estudos complementares e reforço da estrutura buscouse no Brasil uma empresa com experiência, conhecimento apropriado e de credibilidade, chegando então por intermédio de referências à Exata Engenharia e Assessoria, sendo este estudo coordenados pelos Engenheiros Dr. Antônio Carmona Filho e MSc. Thomas Garcia Carmona.

\section{ENSAIOS PRELIMINARES DE REATIVIDADE}

Os consultores, logo na primeira visita levantaram a suspeita de reação álcali agregado (RAA), devido à existência de material branco depositado sobre algumas fissuras. 
Para realização das análises de durabilidade e reações expansivas foram extraídos 3 testemunhos de concreto, os quais foram enviados à ABCP - Associação Brasileira de Cimento Portland, onde constatou a presença de material branco (MB) ao redor do agregado graúdo na parte externa dos testemunhos, que foi observado através de lupa estereoscópica, conforme figuras 05 e 06 . O material branco ao redor do agregado graúdo é típico da reação álcali agregado (RAA).

Figuras 05 e 06 - Borda de material branco (MB) depositado ao redor do agregado graúdo, típico de RAA.

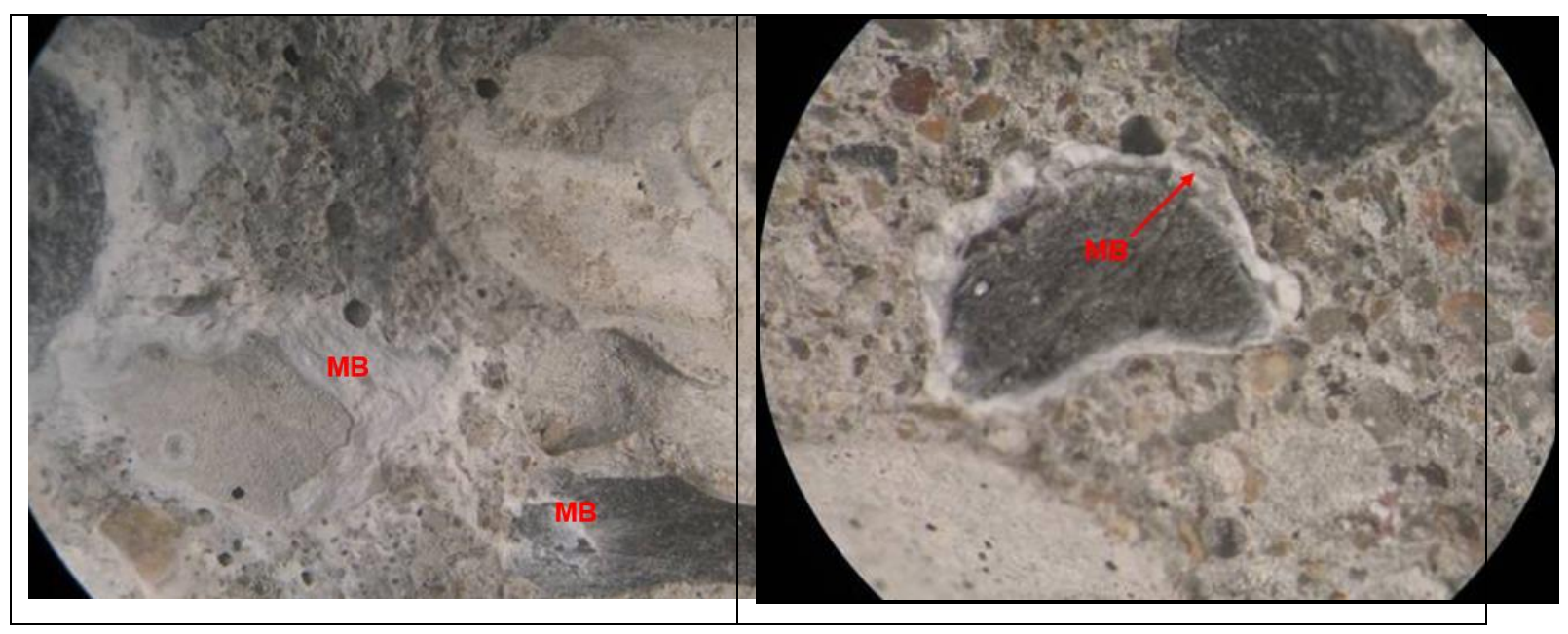

Fonte: Lotufo Engenharia e Construções Ltda. (2010).

O estudo também encontrou expressiva presença de etringita, e de acordo com CARMONA FILHO e GARCIA CARMONA (2011) o cimento portland contém aluminato tricálcico que na hidratação se combinará em sua maior parte na forma de monosulfato hidratado e este em contato com íons sulfato, umidade e a portlandita se converte em etringita, que pode levar à fissuração do concreto. A figura 07, apresenta 0 gráfico com os resultados da varredura eletrônica/EDS no qual observa-se a composição aproximada da etringita 
Figura 07 - Gráfico mostrando a composição aproximada da etringita com elevado conteúdo de enxofre (S).

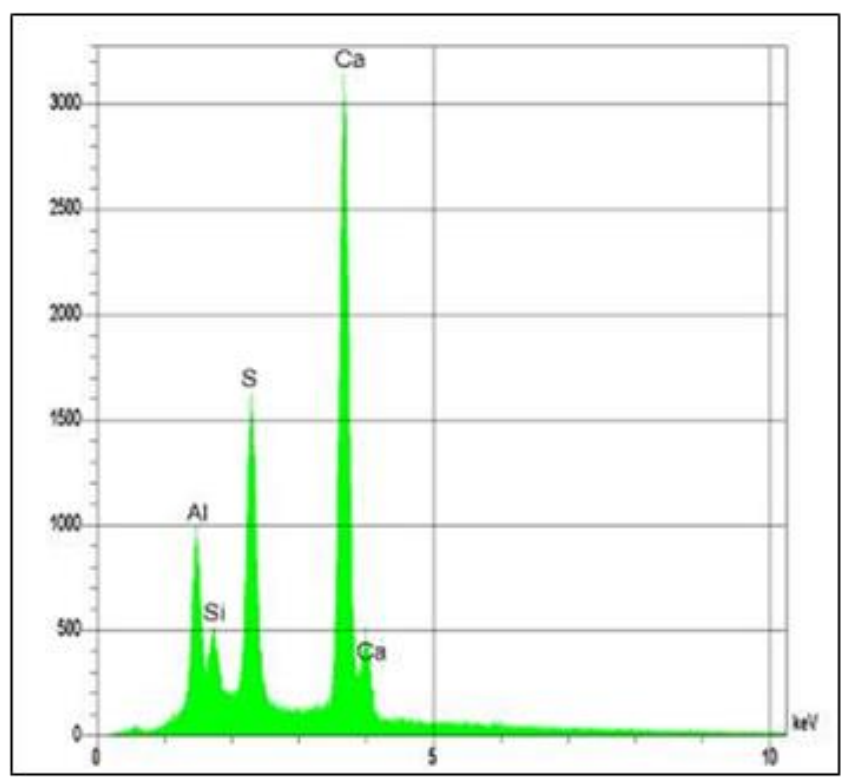

Fonte: Lotufo Engenharia e Construções Ltda. (2010).

\section{ENSAIOS ADICIONAIS}

Dada a suspeita de reação expansiva por formação de etringita secundária decidiu-se realizar determinações de teor de sulfatos no concreto original dos pilares, com a coleta de amostras em pó, conforme figura 08.

Figura 08 - Retirada de amostra para determinação do teor de sulfatos no pilar.

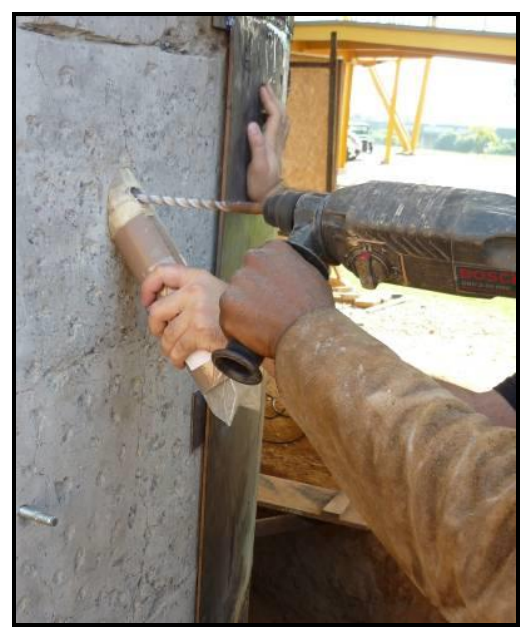

Fonte: CARMONA FILHO e GARCIA CARMONA (2011)

Os resultados apresentaram elevados teores de sulfatos, superiores ao valor de 4\% permitido pela norma NBR 11578:1991, porém os relatórios de controle de qualidade da cimenteira do período de maio a dezembro de 2006 (execução da obra) indicam que 
todos os valores são inferiores a $4 \%$ com média de $2,69 \%$ e nos dados da análise química dos aditivos utilizados na época da obra, não consta a existência de Sulfatos.

Como dado adicional a Exata Engenharia solicitou a retirada de 2 testemunhos para acompanhamento de suas expansões ao longo do tempo (figura 09), empregando dois tipos de exposição, uma acelerada para comparação com os limites de norma e outra tentando simular as condições de exposição no local.

Figura 09: Retirada de testemunhos para ensaios de expansibilidade.

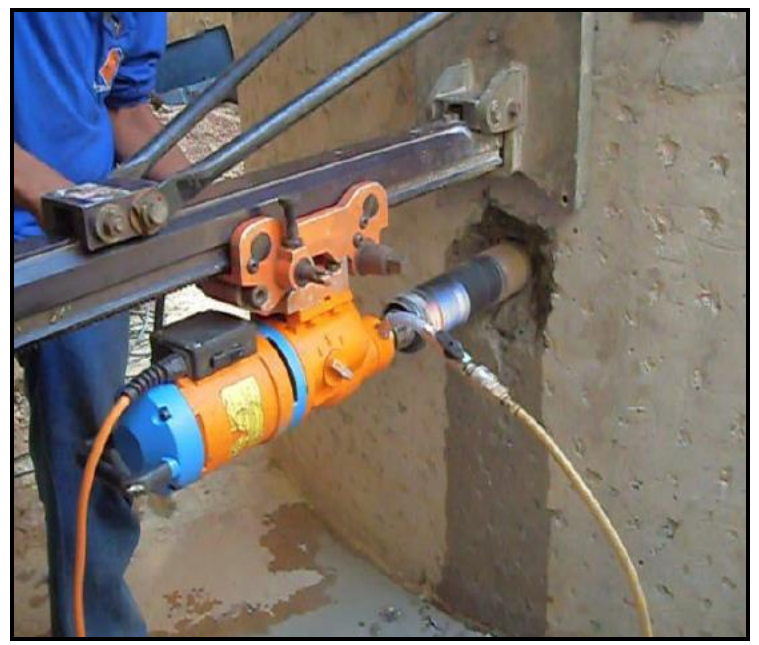

Fonte: Lotufo Engenharia e Construções Ltda. (2010).

Conforme CARMONA FILHO e GARCIA CARMONA (2011) no caso do ensaio acelerado o resultado pode ser comparado com o limite de $0,1 \%$ aos 14 dias da NBR 15577:2008, empregado para verificação da efetividade de mitigação da reação em prismas de argamassa. Sendo os resultados superiores ao limite deveriam ser testadas outras formas de mitigação ou a troca do agregado. Entre as possíveis medidas de mitigação seriam indicados cimentos com elevados teores de adições de escória ou pozolana, enquanto que para o caso foi empregado o cimento CP II F 32, que é um cimento sem adições capazes de mitigar as reações de expansão. Mesmo no ensaio normal, ou seja, não acelerado, a expansão pode ser considerada elevada se levarmos em conta as expansões relatadas na literatura entre $0,2 \%$ e $0,5 \%$ ocorridas no decorrer de vários anos em utilização. No caso em estudo se trata de expansão medida em 28 dias e ainda assim desprezando a expansão que já ocorreu desde a concretagem até a data da leitura (aproximadamente 4 anos).

\section{VERIFICAÇÃO ESTRUTURAL}

Com base nas cargas e projetos fornecidos foram realizadas verificações estruturais simplificadas dos pilares, considerando:

- Carga vertical (apoio superior + apoio inferior): $143 \mathrm{tf}$

- Carga horizontal X (apoio superior + apoio inferior): $160 \mathrm{tf}$

- Carga horizontal Y (apoio superior + apoio inferior): $52 \mathrm{tf}$

- Concreto: $\mathrm{C} 25$

- Aço: CA 50 
A primeira verificação realizada foi a de flexo compressão. Conforme esperado essa verificação indicou que a resistência é muito superior à necessária, considerando ou não o efeito da força de compressão existente.

A segunda verificação realizada foi a de pressão em área reduzida que indicou que a resistência ao esmagamento do concreto é muito superior ao necessário. A quantidade de armadura necessária para distribuição da carga vertical é compatível com a originalmente projetada $(8 \mathrm{~mm} \mathrm{C} / 10)$.

\section{PROJETO DE REFORÇO}

Considerando que a expansão por RAA ocorre com o agregado reativo na presença de umidade, decidiu-se realizar um reforço em chapas aderidas com resina epóxi em toda a altura dos pilares.

A espessura da chapa lateral foi de $6,3 \mathrm{~mm}$ e da superior de $10 \mathrm{~mm}$, e também a utilização de chumbadores da de $12,5 \mathrm{~mm}$ com $25 \mathrm{~cm}$ de embutimento no concreto (figuras 10 e 11).

Figura 10 - Pilar em processo de montagem das chapas, após recuperação e escarificação da superfície para melhor aderência da resina.

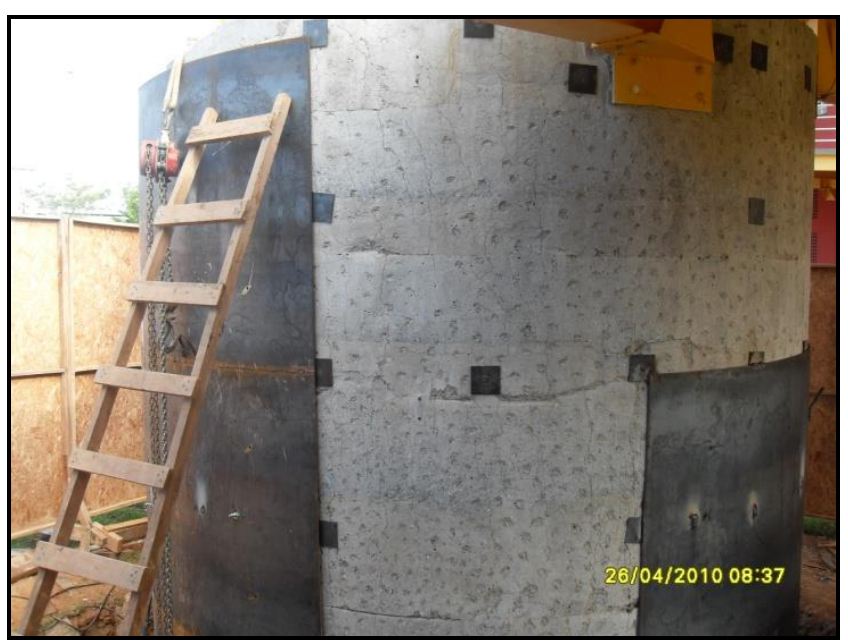

Fonte: Lotufo Engenharia e Construções Ltda. (2010). 
Figura 11 - Sistema de injeção da resina.

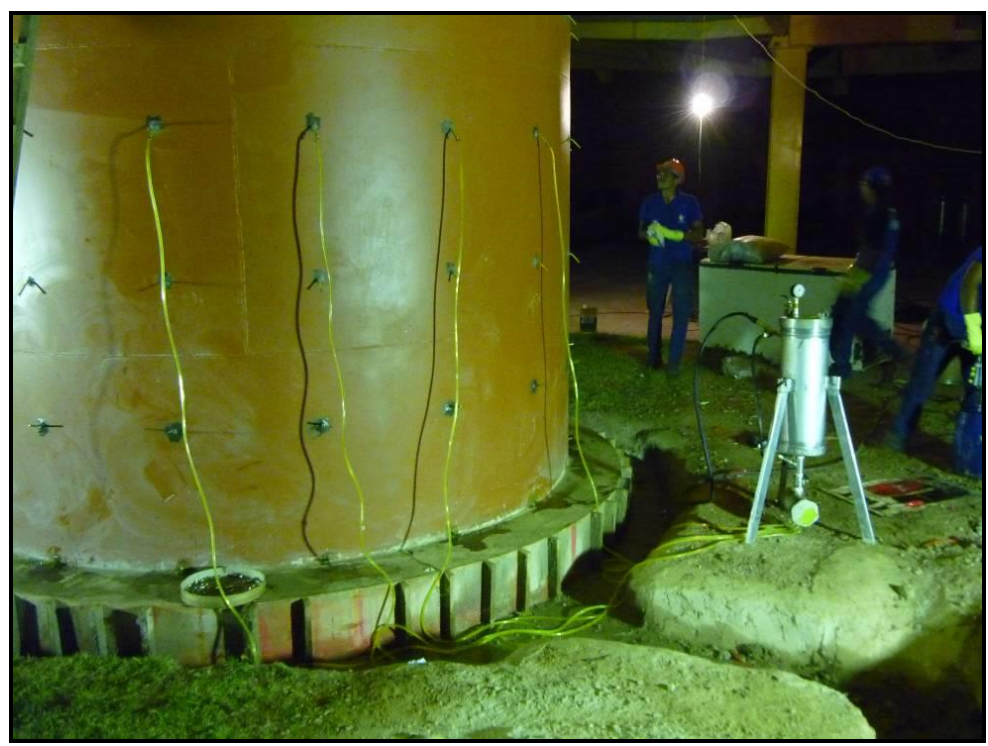

Fonte: Lotufo Engenharia e Construções Ltda. (2010).

\section{CONCLUSÕES OU CONSIDERAÇÕES FINAIS}

No estudo de caso apresentado, ficou clara a existência de reação de expansão, seja ela decorrente reação álcali-agregado (RAA), por formação de etringita secundária ou ambos.

No estudo inicial da obra não se empregou a ABNT NBR 15577:2008, que infelizmente foi publicada em data posterior à construção do ginásio.

As análises de reatividade dos agregados apresentadas pela concreteira foram realizadas fundamentalmente com na norma ASTM C 289 e segundo as quais houve aceitação dos mesmos para uso em concreto. Porém, esse método era o único disponível na época, mas atualmente não é mais recomendado, justamente por se ter constatado que o mesmo não apresentou precisão para identificar a reatividade de agregados que vieram a ocasionar danos estruturais em aplicações reais, situação que diferente da atual normalização.

$\mathrm{O}$ custo do segundo reparo, que incluem a consultoria, materiais e serviços especializados foi de mais de $\mathrm{R} \$ 600.000,00$ (seiscentos mil reais), o que representa cerca de $2,5 \%$ do valor da obra.

\section{AGRADECIMENTOS}

Os autores são gratos à Lotufo Engenharia e Construções Ltda por permitir o acompanhamento das ações e disponibilização de informações e dados técnicos. 


\section{REFERÊNCIAS}

CARMONA FILHO, A.; GARCIA CARMONA, T. Análise, danos e reforços dos apoios da cobertura do ginásio poliesportivo de Cuiabá-Mato Grosso-Brasil (147BR), XI Congresso Latinoamericano de Patologia de La Construcción, CONPAT 2011, La Antigua Guatemala, Guatemala, 2011.

GALLO, Guilherme; SANCHES, Leandro; MEDEIROS, Marcelo; ANDRADE, Tibério. Medidas preventivas para reação álcali-agregado (RAA) no concreto. Revista Concreto \& Construções, edição 46. São Paulo, 2007.

Lotufo Engenharia e Construções Ltda. - Relatórios técnicos. Cuiabá - MT, 2010.

Secretaria de Esportes - Governo do Estado de MT - 2013. Disponível em: $<$ http://www.esportes.mt.gov.br/html/vilaOlimpica.php?codigoVilaOlimpica=1 $>$. Acesso em: 23 nov. 2013. 